\title{
Current and future applications of nanotechnology in plastic and reconstructive surgery
}

\author{
Dana K. Petersen', Tate M. Naylor², Jon P. Ver Halen ${ }^{3,4,5}$ \\ ${ }^{1}$ Department of Otolaryngology - Head and Neck Surgery, University of Tennessee Health Science Center, Memphis, TN 38163, USA. \\ ${ }^{2}$ Department of Surgical Oncology, School of Medicine, University of Tennessee Health Sciences Center, Memphis, TN 38163, USA. \\ ${ }^{3}$ Department of Surgical Oncology, Division of Plastic, Reconstructive and Hand Surgery, Baptist Memorial Healthcare Corporation, \\ Memphis, TN 38120, USA. \\ ${ }^{4}$ Department of Surgical Oncology, Vanderbilt Ingram Cancer Center, Nashoille, TN 37232, USA. \\ ${ }^{5}$ Department of Surgical Oncology, St Jude Children's Research Hospital, Memphis, TN 38105, USA.
}

Address for correspondence: Dr. Jon P. Ver Halen, Department of Surgical Oncology, Division of Plastic, Reconstructive and Hand Surgery, Baptist Memorial Healthcare Corporation, Memphis, TN 38120, USA. E-mail: jpverhalen@gmail.com

\begin{abstract}
Although nanotechnology is a relatively young field, there are countless biomedical applications in use or under investigation. Many specialties have benefitted from nanoscale refinements of diagnostic and therapeutic techniques. Plastic and reconstructive surgery is an incredibly diverse specialty, encompassing craniofacial and hand surgery; trauma, oncologic and congenital reconstruction; burn care, and aesthetic surgery. Advances in nanotechnology have significantly impacted wound management, topical skin care, implant and prosthetic design, tissue engineering, and drug delivery systems. Currently, plastic surgeons are researching the utility of nanoscale tools for bone regeneration, bone prosthetics, and drug delivery. Nanotechnology will continue to build upon preceding discoveries, and its biomedical applications in the field of plastic and reconstructive surgery will expand significantly.
\end{abstract}

Key words:

Bone graft, burns, drug delivery, implants, nanotechnology, tissue engineering, wound care

\section{INTRODUCTION}

Nanotechnology can be defined as the science of design, synthesis, characterization and application of materials and extremely small devices. The smallest functional unit of this technology, in at least one dimension, is on the nanometer scale, which is one billionth of a meter. ${ }^{[1-3]}$ Nanotechnology is the design and engineering of novel products that interact with biological, electrical and chemical systems on the atomic level, thus yielding a level of specificity and specialization that was not feasible in

\begin{tabular}{|l|l|}
\hline \multicolumn{2}{|c|}{ Access this article online } \\
\hline Quick Response Code: & Website: \\
\hline & www.parjournal.net \\
\cline { 2 - 2 } & \\
\hline & \\
\hline
\end{tabular}

the past. In the 1950's, European researchers discovered formation of an active biological field from the oxidation of titanium when exposed to air. They identified that this promotes living tissue ingrowth. ${ }^{[4]}$ This phenomenon was used to take a tremendous leap in medical technology, specifically in bone implant applications. Nanomedicine is a subdivision of nanotechnology that employs highly specific molecular interventions for both the diagnosis and treatment of disease processes. Currently, nanomedicine has allowed advancement in the fields of drug delivery systems, gene therapies, body and organ imaging, surgical tools, and diagnostic procedures.

\section{SOFT TISSUE REPAIR AND HEALING}

Wound and burn care are two areas of clinical care that are already benefitting from developments in nanotechnology. ${ }^{[5]}$ Wound dressings constructed using nanoscale fabrication techniques can greatly improve wound healing. Nanofibers may be created from various 
materials using manufacturing techniques on a nanoscale. The nanofibers provide a three-dimensional structure that mimics the native extracellular matrix (ECM) while the host tissue regeneration replaces the scaffold. Nanofiber scaffolds provide several properties that are essential for tissue repair: mechanical integrity, temperature control, fluid absorption, and gas exchange.

In rat models, scaffolds made of collagen nanofibers accelerate acute wound healing by enhancing capillary and fibroblast proliferation. ${ }^{[6]}$ In a study by Choi et al. ${ }^{[6]}$ recombinant human epidermal growth factor (EGF) was immobilized on electrospun biodegradable nanofibers to treat diabetic ulcers in a rat model. Human primary keratinocytes were cultivated on the nanofiber matrix to investigate the effect of EGF nanofibers on their differentiation. Wound healing effect of the EGF nanofibers was confirmed in diabetic animals with dorsal wounds. In in vivo wound healing studies, the EGF-nanofibers group was superior to control groups (conventional dressing, nanofibers alone, or EGF solutions). This study showed that EGF-conjugated nanofibers could potentially be employed as a novel wound healing material by increasing proliferation and phenotypic expression of keratinocytes in diabetic wounds.

Chitin and chitosan nanofibrils are nanocrystals of natural polysaccharides derived from the exoskeletons of crustaceans. These fibrils have been used in a variety of formulations to aid wound healing. Muzzarelli et al. ${ }^{[7]}$ showed in murine models that different formulations of chitin nanofibrils almost lead to normal physiologic repair of wounds. They subjected various formulations of dibutyryl chitin (DBC), a modified chitin carrying butyryl group at the three and six positions, to a battery of in vitro and in vivo tests. The DBC's were then incorporated into a 5-methylpyrrolidinone chitosan solution and submitted to freeze-drying to produce a reinforced wound dressing material, which was then tested in vivo in full thickness wounds in rats. The rats had full thickness dorsal wounds bilaterally and treated with the experimental agent on one side, and control on the contralateral side. The animals were studied at either 7 or 14 days and the skin of each surgical wound was excised. The use of $4 \mathrm{~mm} \times 4 \mathrm{~mm}$ pieces as wound dressings resulted in significantly less cutaneous scarring, as measured by collagen I/collagen III rations, and as measured clinically.

Chitin nanofibrils/chitosan glycolate can be manufactured into a spray, gel or impregnated onto a dressing for wound care. Using a rat model, Mattioli-Belmonte et $a .^{[8]}$ demonstrated that each of these delivery systems has a specific application: use for superficial abrasions, shallow wounds in aesthetic areas, and slow healing dermo-epidermal wounds, respectively. Enhanced tissue repair and reduced scarring was seen in all the applications. Although the results from all of these studies are impressive, they have not been examined in human clinical trials.

Silver has long been heralded for its antimicrobial properties and has demonstrated efficacy against multi-drug resistant organisms as well as exhibiting antiinflammatory properties..$^{[9,10]}$ Nanoscale fabrication techniques have allowed manufacturing silver into nanoparticles, which markedly increases the rate of silver ion release, and thus increasing its clinical utility. ${ }^{[10,11]} \mathrm{A}$ nanocrystalline silver dressing was recently evaluated in chronic wounds by Sibbald et al..$^{[9]}$ In a prospective, uncontrolled study, a variety of chronic, nonhealing wounds (foot, pressure, and venous stasis ulcers, and miscellaneous wounds) were treated with a nanocrystalline sliver dressing [Figure 1]. Surface bacterial counts were found on semi-quantitative swabs to be significantly diminished in those wounds treated with nanocrystalline dressing. Since bacteria contribute to tissue damage leading to poor wound healing, the decreased bacterial load from silver nanocrystalline dressing facilitates wound healing. In addition, growth factors have been shown to play a critical role in the proliferative phase of wound healing. Growth factors serve to attract the cells necessary for fibroblast and epithelial cell growth and migration, as well as initiating the formation of new blood vessels into the area of injury. Novel polymerized nanocarriers have been produced, which can provide for consistent and significant dosages of growth factors. The growth factors are embedded into the polymerized nanocarriers that allow sustained release of these bioactive molecules. The nanocarrier drug delivery system has been successful in treating wounds in a clinical setting. ${ }^{[10]}$

The cosmetic and topical skin care industries have also benefited from advances in nanotechnology. For example, micronized zinc oxide and titanium dioxide $\left(\mathrm{TiO}_{2}\right)$ are used in sunscreen manufacturing by functioning as ultraviolet blockers in these products. Their nanoscale fabrication increases their transparency on skin and allows increased user compliance. In addition, it also increases their refractive index, resulting in a "stronger" sunscreen. ${ }^{[12]}$ Lipid nanoparticles have been added to various cosmetic and dermal products to increase contact with the stratum corneum. Therefore, it allows increased drug penetration into the skin, improved hydration through their occlusive properties, and provide controlled release of active ingredients. $^{[13]}$ In an open clinical trial, fullerene gel applied to patients with acne vulgaris showed a significant reduction cutaneous inflammation and infection, suggesting yet another application of nanotechnology in skin care. ${ }^{[14]}$

\section{IMPLANTS AND PROSTHESES}

In 2012, breast augmentation and implant-based breast reconstruction after mastectomy were the most common plastic surgery procedures. Breast implants that contain nanofiber coatings for the delivery of tumor-specific anticancer drugs are currently being evaluated. ${ }^{[15]}$ This technology has the potential to revolutionize cancer care, by facilitating area-specific chemotherapy to the tumor bed while alleviating some of the undesirable effects of current systemic chemotherapy regimens. In addition, 


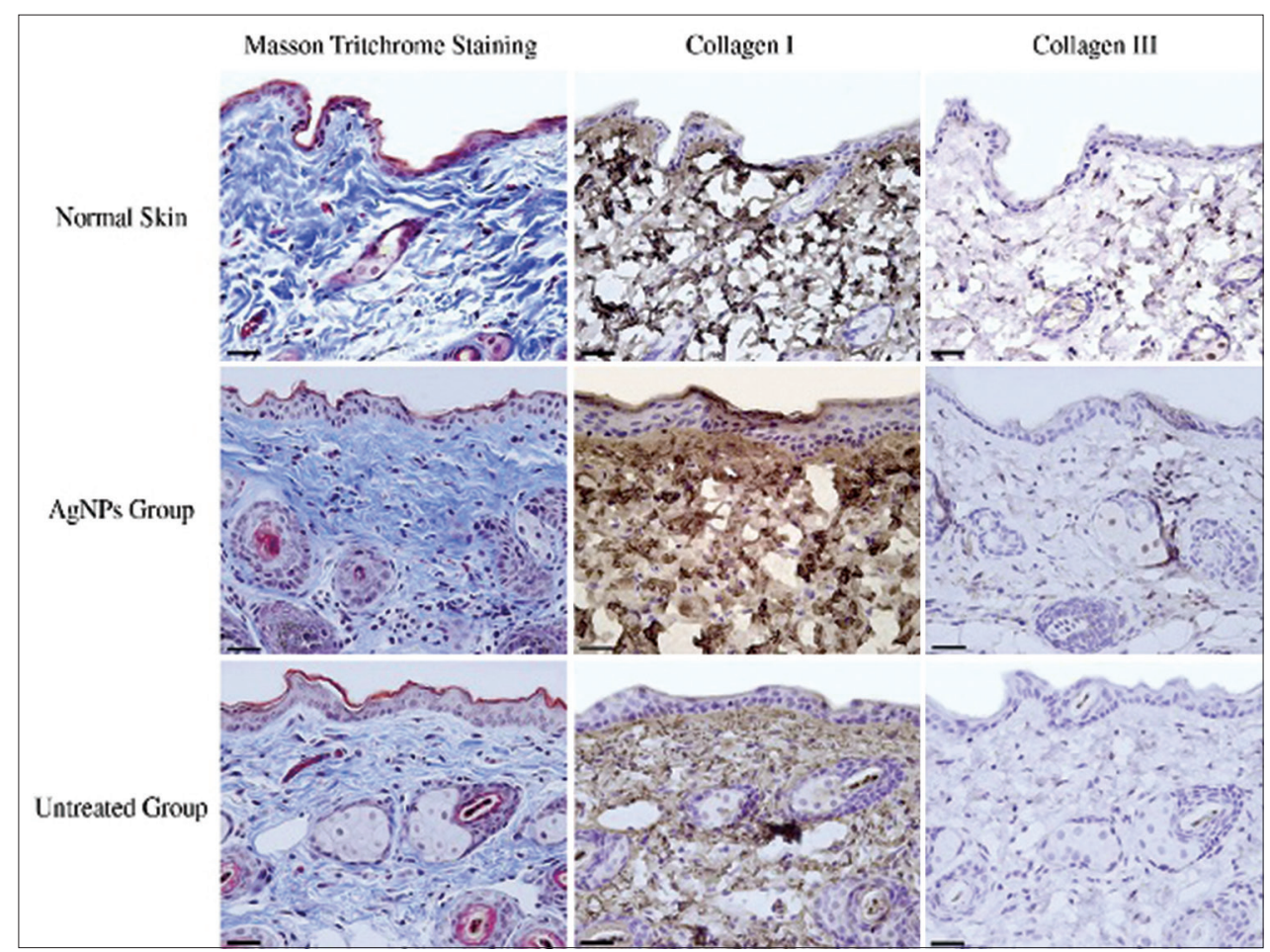

Figure 1: Histological staining of healed skin in each experimental group. Masson trichome staining shows the distribution and density of collagen protein in healed skin in various groups. Collagen protein was stained blue, nuclei are stained black and the background (muscle, cytoplasm and keratin) are stained red. Immunohistochemistry staining shows the expression of collagen Type I and Type III of healed skin in normal skin, silver treated, and untreated groups, respectively (scale bar: $20 \mu \mathrm{m})^{[9]}$ (used with permission)

utilizing nanoscale technology in manufacturing can improve the strength of breast implants. The shell of silicone breast implants is made up of cross-linked and reinforced silicone rubber nanocomposite. The silicone rubber is weak and, therefore, must be reinforced, most commonly with nanosized $\mathrm{SiO}_{2}$. Finally, even with modern breast implants, capsular contracture continues to be one of the significant long-term complications of long-term breast implant placement. It has been demonstrated in a rat model that surface modification of implants with antifibrotic drugs (e.g. halofuginone) can decrease capsule formation. ${ }^{[16]}$

\section{TISSUE AND ORGAN ENGINEERING}

Nanotechnology has been used to construct and repair various tissues utilized in plastic surgery. Electrospun nanofiber matrices have been developed for skeletal muscle regeneration in both in vitro and in vivo experimental models. ${ }^{[17]}$ Reconstructive plastic surgeons are currently using cartilage engineering that has been utilized in orthopedic surgery for many years. The engineering of auricular cartilage for ear reconstruction is an established technique. Additionally, nasal cartilage is being examined for complex nasal reconstruction after cancer, trauma, or congenital defects. ${ }^{[18]}$ Artificial skin has long been used for the treatment of skin defects. Currently, the use of scaffolds composed of polylactic and polyglycolic acids embedded with various growth factors are used to improve skin healing. ${ }^{[19,20]}$ With precise manufacturing techniques and the utilization of novel biomaterials, the development of these products can provide enhanced aesthetic appearance after reconstruction. This has been proven to be safe, reliable, and reproducible.

\section{NERVETUBULIZATION}

Nerve regeneration is an area of particular interest to both plastic surgeons and nanotechnology researchers. Plastic surgeons perform the majority of the peripheral nerve surgeries involving the hands, face, and trunk. ${ }^{[21,22]}$ Traumatic nerve injuries resulting in loss of nerve tissue over $5 \mathrm{~mm}$ frequently require nerve grafting, often from an autologous source. Donor sites for this procedure, however, are limited. To avoid the morbidity of autologous nerve grafting, nanoscale manufacturing techniques have been employed to develop new approaches in peripheral nerve repair. Tubular and porous nanostructured conduits, using various natural materials, have been developed to guide regenerating nerves. These structures have been loaded with various biomaterials or cell types (e.g. embryonic stem cells, Schwann cells, neural stem cells) to aid regeneration. Chitosan nanofiber mesh tubes were studied in sciatic nerve injuries in a rat model by Wang et al., ${ }^{[23]}$ in which they noted partial recovery of sensory function as the nerves elongated through the tubes. Biodegradeable micropatterned scaffolds that mimic the extracellular membrane can also be coated with laminin and seeded with Schwann cells to guide neuron alignment and promote axon regeneration after injury. ${ }^{[19]}$ Currently, researchers are designing neural interfaces between the peripheral and central nervous system, and limb prostheses for patients with traumatic amputations and spinal cord injuries. . $^{24,25]}$ 


\section{NANOTECHNOLOGY IN BONE BIOLOGY AND REPAIR}

Current developments in bone matrix depend on the understanding that the bone microenvironment is made up of progenitor cells, mineralized ECM scaffold, soluble chemical signals (such as cytokines), and mechanical stimuli. ${ }^{[26]}$ Nanoscale fabrication techniques can improve each of these components. Scaffolds made of nanomaterials provide a geometric porous structure that allows osteoblastic differentiation. ${ }^{[27]}$ Such techniques are conceptually simple, yet were not technically possible until the development of modern nanoscale fabrication techniques. Advances in fabrication and manufacturing make nanotechnology an exciting and powerful tool in the development of bone reconstruction.

\section{BONE PROSTHESES}

Nanotechnology can be used to manipulate the surfaces of standard bone replacement implants to maximize tissue ingrowth, while minimizing inflammation. Raimondo et al. ${ }^{[28]}$ recently investigated the use of electron beam absorption to resurface standard titanium and polyethylene (PE) implant surfaces. Then, they evaluated them for surface characterization, surface energy and contact angles, and osteoblast and endothelial cell adhesion [Figure 2]. They found that the nano-roughened surfaces were more favorable in each category. While unmodified titanium surfaces demonstrated excellent adhesion of both osteoblasts and endothelial cells, once modified, the PE surface showed significantly increased osteoblast adhesion and showed similar endothelial cell adhesion. This study introduces a novel process to efficiently nano-roughen materials and provides an additional example of nanotechnology use to enhance the performance of standard synthetic materials.

Liu and Webster ${ }^{[29]}$ re-emphasizing the importance of the homogenous dispersion of poly-DL-lactic-co-glycolic acid (PLGA) nanoparticles for optimal enhancement of cell adhesion. They demonstrated that PLGA prosthetics enhanced with a well-dispersed nanoceramic coating

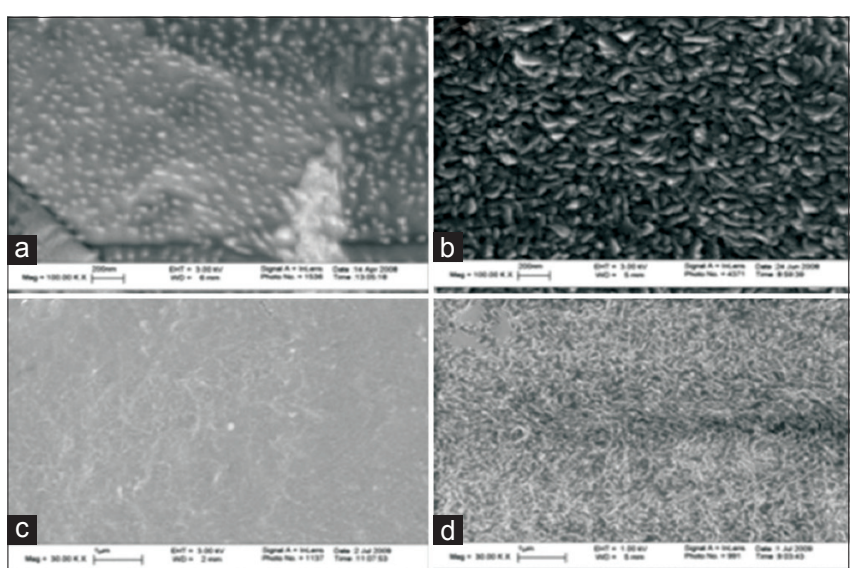

Figure 2: Scanning electron microscopy images of (a) conventional titanium (Ti), (b) nanorough Ti, (c) conventional polyethylene (PE), and (d) nanorough PE. Scale bars in (a) and (b) are $200 \mathrm{~nm}$ while (c) and (d) are $1 \mu \mathrm{m}^{[28]}$ (used with permission) had improved load-bearing limitations. This improved mechanical strength was most likely due to the strong bonds between nanoparticles and PGLA, as conveyed by the fine ultrastructure of the particles. This enhancement of mechanical strength, through the application of nanoparticles, is a previously underappreciated finding in nanomaterials. Finally, this work highlights that the three-dimensional structure of nanoparticles and its interactions can increase their applications.

Hydroxyapatite (HA) is currently used to fill bone defects by itself or as a prosthetic coating. While HA has advantages over other bioceramics, such as creating strong bonds with native tissues, it lacks a homogeneous degradation phase. Given the nanoscale architecture of native bone crystals, manufacturing HA on a nanoscale would theoretically improve its utility. Poinern et al. ${ }^{[30]}$ investigated the effects of thermal and ultrasonic techniques for the development of these particles and demonstrated that either technique can generate particles of similar consistency. Abd El-Fattah et al. ${ }^{[31]}$ histomorphometrically analyzed the tissue by growth and scaffold degradation in three groups of rats with identical bone defects: one filled with mirco-HA, one with nano-HA and one control group without filler. They found increased reactive bone formation and biocompatibility in nano-HA group compared with other groups. These findings have immediate implications for improving the utility of HA for craniofacial, hand, extremity, and truncal bone reconstructive applications.

\section{BONE REGENERATION}

In addition to aiding the development of bone prosthetics, nanotechnology also provides many inroads to improve bone regeneration. The induction of progenitor cells into osteoblasts is an important component of bone regeneration. A novel application of nanotechnology to achieve this goal is the application of specific nanoscale surfaces to produce specific cellular responses, such as osteoblastic differentiation. Oh et al. ${ }^{[27]}$ investigated the effect of culturing human mesenchymal stem cells (hMSC) on $\mathrm{TiO}_{2}$ nanotubes ranging in size from $30 \mathrm{~nm}$ to $100 \mathrm{~nm}$. They found that the larger nanotubes forced the elongation of the hMSCs and consequently encouraged differentiation into osteoblastic cell lines. They proposed that smaller nanotubes capture local proteins easily and establish an ECM-like environment allowing for easy hMSC adhesion. In larger nanotubes, there is less capture of local proteins, and the hMSCs require to stretch and develop filopodia to elongate across the surface and establish adequate adhesion [Figure 3]. This geometrical manipulation provides the cytoskeletal stress theorized to induce osteoblastic differentiation. This technique could feasibly improve previous methods of osteoinduction that involve gene therapy. ${ }^{[32]}$

\section{NANOTECHNOLOGY IN MAXILLOFACIAL SURGERY}

Nanotechnology has the potential to bring enormous changes to the fields of maxillofacial surgery and 


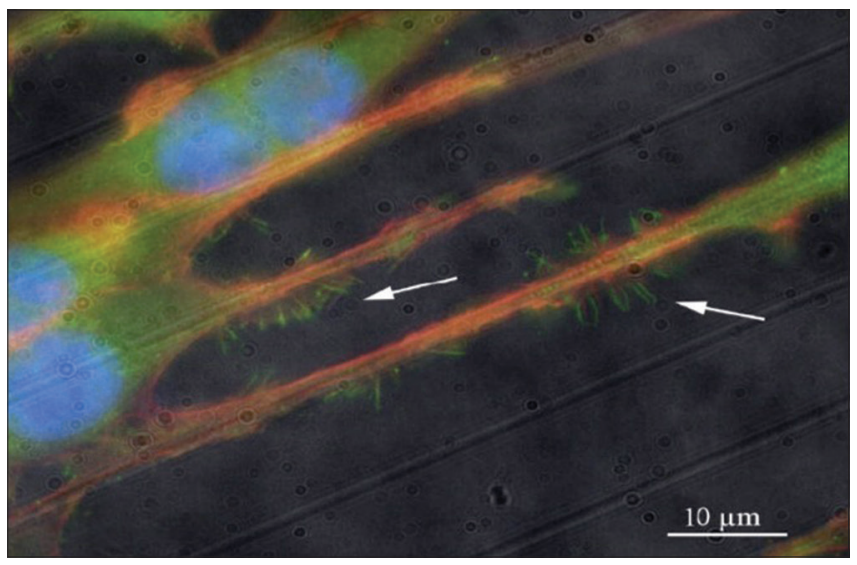

Figure 3: Filopodia of endothelial cells induced by nanotopography ${ }^{|27|}$ (used with permission)

dentistry through the aid of nanorobotics, nanomaterials, and biotechnology. ${ }^{[33]}$ Nanorobots have a diameter of $0.5-3 \mu \mathrm{m}$ and are made of components sized from $1 \mathrm{~nm}$ to $100 \mathrm{~nm}$. They can be programmed, thus enabling clinicians to execute accurate procedures at the cellular and molecular levels. Specifically, they have roles in local anesthesia, diagnostics, therapeutics, dental and maxillofacial hard tissue repositioning, and dentifrice. In maxillofacial surgery, nanomaterials can be used as bone replacement materials, prosthetic implants, dental fillers, dental restorative materials, impression materials, and even for orthodontic wires exhibiting very high strength and excellent deformability, corrosion resistance, and surface finish. Finally, tissue engineering with natural nanomaterials holds the potential to completely reconstruct a patient's dentition and craniofacial skeleton.

\section{DRUG DELIVERY}

Nanoscale technologies have numerous applications in drug delivery [Table 1]. Bone infections can be catastrophic and are difficult to manage even in the age of modern antibiotics and best surgical techniques. ${ }^{[34]}$ Plastic surgeons are frequently involved in the management of these problems because they provide technical expertise with vascularized tissue transfer and soft tissue reconstruction. Deep tissue infection with multiple drug resistant organisms coupled with the morbidity of serial operations and potentially toxic systemic therapies begs for the introduction of new approaches. The antimicrobial properties of silver have long been appreciated, and current nanotechnological techniques have allowed the production of nanoscaled silver particles with a very high surface to mass ratio. Zheng et al. ${ }^{[35]}$ examined PLGA composite grafts treated with nanosilver compared with PLGA controls [Figure 4]. They were able to demonstrate that this composite had strong antimicrobial properties and that the presence of the nanosilver did not affect the osteoinductive properties of PLGA in the presence of bone morphogenic protein- 2 . In a rat model, nanosilver-PLGA composite grafts demonstrated complete healing without residual bacteria, while control animals had residual bacterial contamination. This study

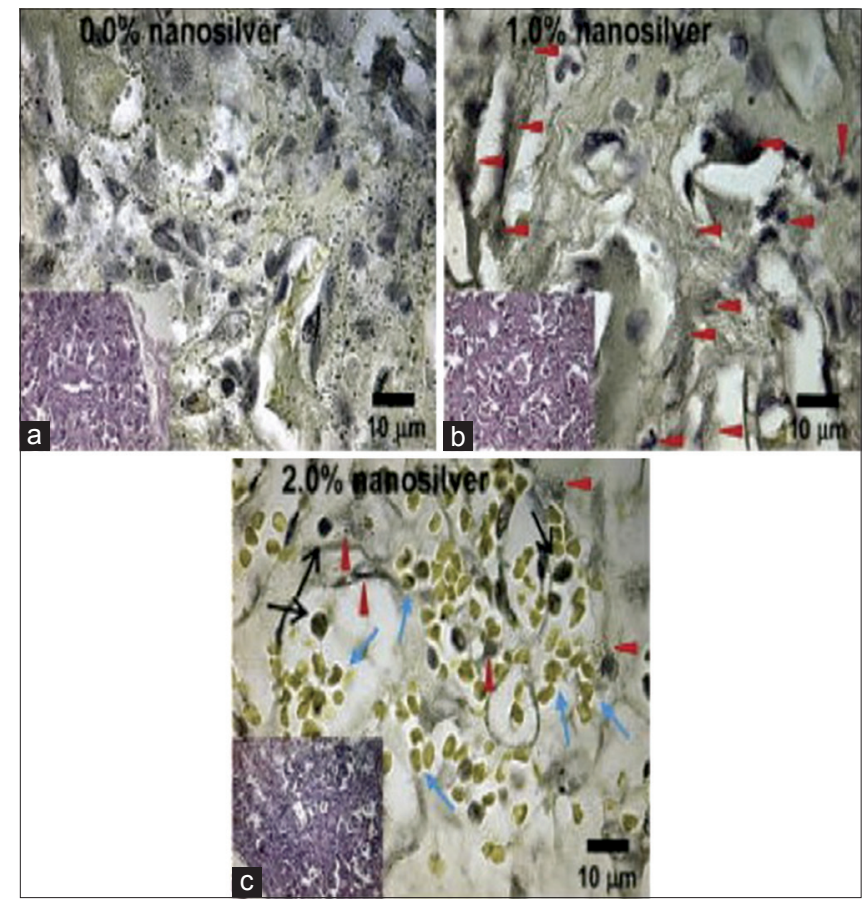

Figure 4: In vivo antibacterial activity of nanosilver particle-polyDL-lactic-co-glycolic acid (PLGA) composite grafts. After 2-week contamination with 108 CFU Staphylococcus aureus Mu50, rat femoral segmental defects with implanted grafts were harvested, fixed, decalcified, embedded, sectioned and stained with Taylor modified Brown and Brenn Gram-stain as well as $\mathrm{H}$ and E. (a) Compared to serious bacterial infection (black dots) found in control PLGA grafts, (b) $1.0 \%$ nanosilver-PLGA composite grafts significantly reduced bacterial survival to colonized collation (red arrows). (c) On the other hand, only limited bacterial colonies (red arrows) were observed in $2.0 \%$ nanosilver particle-PLGA composite grafts in vivo, and more red blood cells (blue arrows) were found in the grafts instead of phagocytes (black arrows) ${ }^{[35]}$ (used with permission)

Table 1: Nanoscale drug delivery technologies ${ }^{[1]}$ (used with permission)

\begin{tabular}{|c|c|c|}
\hline $\begin{array}{l}\text { Drug } \\
\text { delivery } \\
\text { technology }\end{array}$ & Materials & $\begin{array}{l}\text { Nanostructure } \\
\text { forms }\end{array}$ \\
\hline Biologic & $\begin{array}{l}\text { Lipids } \\
\text { Peptides } \\
\text { Nucleic acids } \\
\text { Polysaccharides } \\
\text { Viruses }\end{array}$ & $\begin{array}{l}\text { Vesicles, nanotubes, } \\
\text { rings, nanoparticles }\end{array}$ \\
\hline Polymeric & $\begin{array}{l}\text { Poly (lactic acid) } \\
\text { Poly (glycolic acid) } \\
\text { Poly (alkylcyanoacrylate) } \\
\text { Poly (3-hydroxybutanoic acid) } \\
\text { Poly (organophosphazene) } \\
\text { Poly (ethylene glycol) } \\
\text { Poly (caprolactone) } \\
\text { Poly (ethylene oxide) } \\
\text { Poly (amidoamine) } \\
\text { Poly (L-glutamic acid) } \\
\text { Poly (ethyleneimine) } \\
\text { Poly (propylene imine) }\end{array}$ & $\begin{array}{l}\text { Vesicles, spheres, } \\
\text { nanoparticles, } \\
\text { micelles, dendrimers }\end{array}$ \\
\hline $\begin{array}{l}\text { Silicon } \\
\text { based }\end{array}$ & $\begin{array}{l}\text { Silicon } \\
\text { Silicon dioxide }\end{array}$ & $\begin{array}{l}\text { Porous, } \\
\text { nanoparticles, } \\
\text { nanoneedles }\end{array}$ \\
\hline $\begin{array}{l}\text { Carbon } \\
\text { based } \\
\text { metallic }\end{array}$ & $\begin{array}{l}\text { Carbon } \\
\text { Gold } \\
\text { Silver } \\
\text { Palladium } \\
\text { Platinum }\end{array}$ & $\begin{array}{l}\text { Nanotubes, } \\
\text { fullerness, } \\
\text { nanoparticles, } \\
\text { nanoshells }\end{array}$ \\
\hline
\end{tabular}


shows that silver can be used as an antimicrobial agent in grafts while previous studies showed its topical use.

Kose et al. ${ }^{[36]}$ examined silica-based mesoporous materials to characterize the features that determine the loading capacity and delivery of medications integrated into these devices. They specifically focused on silica-based mesoporous materials because they can be manufactured with a high degree of homogeneity with a tunable pore size. Their work highlights the importance of pore size, volume, and surface area in both drug adsorption and drug elution from the device.

Nanotechnology has further applications beyond the fabrication of devices and materials on the nanoscale. Nanotechnology also allows us to study and quantify biological processes at this level using various techniques. Differences of regional bone on the nanoscale may allow for improved or novel harvesting techniques in addition to infrequently used donor sites for graft harvest. Through this knowledge, we can improvise the architecture of materials to increase success rate in tissue reconstruction. Leong et al. ${ }^{[37]}$ have utilized tissue characterization on the nanoscale to categorize the various tissues present during bone callus formation. Understanding bone healing biology at the nanoscale will help us develop ways to improve this process for reconstructive purposes.

\section{CANCERTREATMENT}

Cancer treatment often involves multiple modalities, including surgery, chemotherapy, and radiation therapy. The single most important predictor of patient survival for cancer is complete surgical resection. Nanometer-sized particles such as quantum dots and colloidal gold have novel size-tunable properties that neither discrete molecules nor bulk materials can provide. ${ }^{[38]}$ These particles have the potential for tumor localization, tumor margin detection, identification of important adjacent structures, mapping of sentinel lymph nodes, and detection of residual tumor cells or micrometastases. Contrast agents containing such particles can be accumulated in solid tumors through passive and active targeting mechanisms. In addition, intraoperative imaging can be used to overcome problems with tissue penetration of traditional optical methods [Figure 5]. Such agents include quantum dots, and surface-enhanced Raman scattering nanoparticles. Evaluating the long-term fate and toxicity of nanoparticles remains a challenge. Finally, it is important to design agents that are accumulated in tumors, but are cleared from other organs and tissues.

In conclusion, nanotechnology has a vast array of applications in plastic and reconstructive surgery [Table 2].

Table 2: Summary of nanotechnology applications in plastic and reconstructive surgery

\begin{tabular}{|c|c|c|}
\hline Material & Device & Application \\
\hline $\begin{array}{l}\text { Lipids, peptides, nucleic acids, } \\
\text { polysaccharides, viruses }\end{array}$ & Vesicles, nanotubes, nanoparticles & Drug delivery \\
\hline $\begin{array}{l}\text { Polymers (poly-lactic acid, glycolic } \\
\text { acid, caprolactone, propylene, etc.,) }\end{array}$ & $\begin{array}{l}\text { Vesicles, spheres, nanoparticles, } \\
\text { micelles, dendrimers }\end{array}$ & Drug delivery \\
\hline Silicone, silicone dioxide & Nanoparticles, nanoneedles & Drug delivery \\
\hline Carbon & Semiconductor quantum dots & Tumor targeting \\
\hline Gold, silver, palladium, platinum & Nanoparticles, nanoshells & Drug delivery, quantum dots, tumor detection \\
\hline Gold & Surface-enhanced Raman scattering & Tumor targeting \\
\hline Poly lactate, poly glycolic acid & Layered scaffolds & $\begin{array}{l}\text { Composite skin grafts, chronic wounds, burn } \\
\text { wounds, skin diseases }\end{array}$ \\
\hline Poly lactate, poly glycolic acid & Contoured scaffolds & Customized fat grafts, breast reconstruction \\
\hline Poly lactate, poly glycolic acid & Flexible scaffolds, bioreactors & Functional muscle grafts, solid organ transplants \\
\hline Poly lactate, poly glycolic acid & Hydrogel scaffolds & $\begin{array}{l}\text { Moldable cartilage scaffolds, craniofacial and skeletal } \\
\text { reconstruction, dental restoration and reconstruction }\end{array}$ \\
\hline Poly lactate, poly glycolic acid & Rigid scaffolds, mineralized substrates & Bone grafts \\
\hline Collagen & Nanofibers & Wound care \\
\hline Chitosan & Nanofibrils & Wound, burn care \\
\hline Silver & Nanoparticles & Wound and burn care \\
\hline Zinc oxide, titanium dioxide & Nanoparticles & Sunscreen \\
\hline Fullerene, lipids & Vesicles, nanotubes, nanoparticles & Skin care products \\
\hline Silicone, silicone dioxide & Nanofiber, nanoparticle & Breast implants \\
\hline Peptides, collagen, PLGA, chitosan & Flexible scaffolds, nanofibers & Nerve conduits \\
\hline PLGA, titanium, polyethylene & Nanoscale surfacing & Bone prostheses and implants \\
\hline Hydroxyapatite & Nanoparticles, implant coating & Bone replacement, implant coating \\
\hline Titanium, carbon & Nanotubes & Bone regeneration scaffolds \\
\hline Carbon, metal colloids & Nanorobots & $\begin{array}{l}\text { Tissue healing, bone replacement, tumor } \\
\text { theronostics, anesthesia }\end{array}$ \\
\hline
\end{tabular}

PLGA: Poly-DL-lactic-co-glycolic acid 


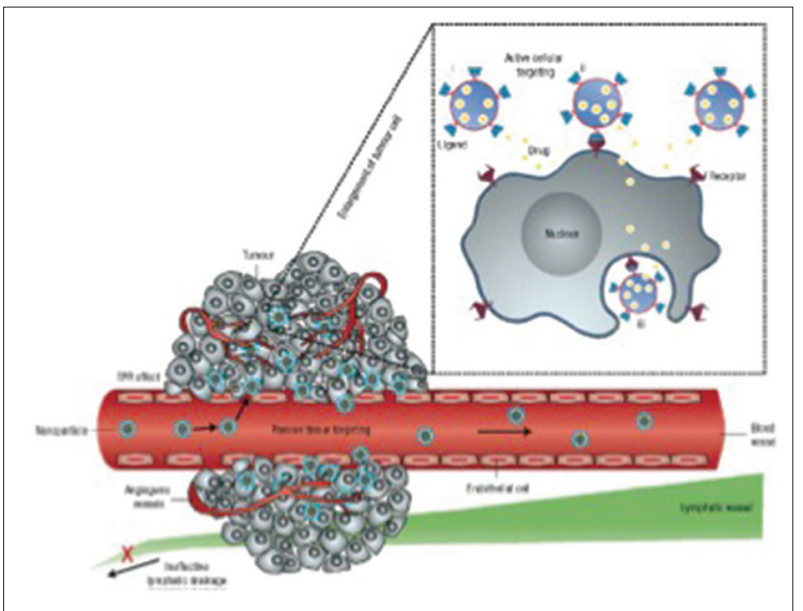

Figure 5: Active versus passive targeting of cancerous tissue. Nanoparticles passively diffuse through the highly permeable endothelial layer of blood vessels in cancer tissue. In addition, decreased lymphatic drainage from solid cancer tissue prevents the nanodrug from returning to the systemic circulation. Active nanodrugs target the tumor tissue with engineered tissue-specific ligands on the surface of the nanodrugl|l| (used with permission)

Specifically, wound management, topical skin care, implant and prosthetic design, tissue engineering, and drug delivery systems have each been influenced by advances in nanotechnology. As our understanding of biology on the nanolevel progresses, the use of this technology will increase exponentially. These characteristics make nanotechnology a powerful tool when applied to all aspects of tissue reconstruction.

\section{REFERENCES}

I. Sahoo SK, Parveen S, Panda JJ. The present and future of nanotechnology in human health care. Nanomedicine 2007;3:20-31.

2. Wong IY, Bhatia SN, Toner M. Nanotechnology: emerging tools for biology and medicine. Genes Dev 2013;27:2397-408.

3. Saadeh Y, Leung T, Vyas A, Chaturvedi LS, Perumal O, Vyas D. Applications of nanomedicine in breast cancer detection, imaging, and therapy.J Nanosci Nanotechnol 2014:14:913-23.

4. Rajesh O, Gitanjaly S, Surbhi M. Nano-Bio-technology excellence in health carenano-bio-technology excellence in health care: a review. Internet J Nanotechnol 2004;I. Available from : http://www.ispub.com/JNNT/I/2/79/0. [Last Accessed on 2014 May 0I].

5. Hromadka M, Collins JB, Reed C, Han L, Kolappa KK, Cairns BA, Andrady T, van Aalst JA. Nanofiber applications for burn care. J Burn Care Res 2008;29:695-703

6. Choi JS, Leong KW, Yoo HS. In vivo wound healing of diabetic ulcers using electrospun nanofibers immobilized with human epidermal growth factor (EGF). Biomaterials 2008;29:587-96.

7. Muzzarelli RA, Guerrieri M, Goteri G, Muzzarelli C, Armeni T, Ghiselli R, Cornelissen M. The biocompatibility of dibutyryl chitin in the context of wound dressings. Biomaterials 2005;26:5844-54.

8. Mattioli-Belmonte M, Zizzi A, Lucarini G, Giantomassi F, Biagini G, Tucci G, Orlando F, Provinciali M, Carezzi F, Morganti P. Chitin nanofibrils linked to chitosan glycolate as spray, gel, and gauze preparations for wound repair. J Bioact Compat Polym 2007;22:525-38.

9. Sibbald RG, Browne AC, Coutts P, Queen D. Screening evaluation of an ionized nanocrystalline silver dressing in chronic wound care. Ostomy Wound Manage 200I;47:38-43

10. Cortivo R, Vindigni V, lacobellis L, Abatangelo G, Pinton P, Zavan B. Nanoscale particle therapies for wounds and ulcers. Nanomedicine (Lond) 2010;5:64I-56.

II. Wu J, Zheng Y,Wen X, Lin Q, Chen X, Wu Z. Silver nanoparticle/bacterial cellulose gel membranes for antibacterial wound dressing: investigation in vitro and in vivo. Biomed Mater 2014;9:035005.
12. Morganti P. Use and potential of nanotechnology in cosmetic dermatology. Clin Cosmet Investig Dermatol 2010;3:5-13.

13. Müller RH, Shegokar R, Keck CM. 20 years of lipid nanoparticles (SLN and NLC): present state of development and industrial applications. Curr Drug Discov Technol 201 I;8:207-27.

14. Inui S, Aoshima H, Nishiyama A, Itami S. Improvement of acne vulgaris by topical fullerene application: unique impact on skin care. Nanomedicine $2011 ; 7: 238-41$.

15. Puskas JE, Luebbers MT. Breast implants: the good, the bad and the ugly. Can nanotechnology improve implants? Wiley Interdiscip Rev Nanomed Nanobiotechnol 2012;4:153-68

16. Zeplin PH, Larena-Avellaneda A, Schmidt K. Surface modification of silicone breast implants by binding the antifibrotic drug halofuginone reduces capsular fibrosis. Plast Reconstr Surg 2010;126:266-74.

17. Klumpp D, Horch RE, Kneser U, Beier JP. Engineering skeletal muscle tissue - new perspectives in vitro and in vivo.J Cell Mol Med 2010;14:2622-9.

18. Oseni A, Crowley C, Lowdell M, Birchall M, Butler PE, Seifalian AM. Advancing nasal reconstructive surgery: the application of tissue engineering technology.J Tissue Eng Regen Med 2012;6:757-68.

19. Gerstle TL, Ibrahim AM, Kim PS, Lee BT, Lin SJ. A plastic surgery application in evolution: three-dimensional printing. Plast Reconstr Surg 2014;|33:446-5I.

20. Hu MS, Maan ZN, Wu JC, Rennert RC, Hong WX, Lai TS, Cheung AT, Walmsley GG, Chung MT, McArdle A, Longaker MT, Lorenz HP. Tissue engineering and regenerative repair in wound healing. Ann Biomed Eng 2014;42:1494-507.

2I. Sivolella S, Brunello G, Ferrarese N, Della Puppa A, D'Avella D, Bressan E, Zavan B. Nanostructured guidance for peripheral nerve injuries: a review with a perspective in the oral and maxillofacial area. Int J Mol Sci 20|4;15:3088-1।7.

22. Konofaos P, Ver Halen JP. Nerve repair by means of tubulization: past, present, future.J Reconstr Microsurg 2013;29:149-64.

23. Wang W, Itoh S, Konno K, Kikkawa T, Ichinose S, Sakai K, Ohkuma T, Watabe K. Effects of Schwann cell alignment along the oriented electrospun chitosan nanofibers on nerve regeneration.J Biomed Mater Res A 2009;91:994-1005.

24. Sedaghati T, Yang SY, Mosahebi A, Alavijeh MS, Seifalian AM. Nerve regeneration with aid of nanotechnology and cellular engineering. Biotechnol Appl Biochem 201 I;58:288-300.

25. Tavangarian F, Li Y. Carbon nanostructures as nerve scaffolds for repairing large gaps in severed nerves. Ceram Int 2012;38:6075-90.

26. Biggs MJ, Dalby MJ. Focal adhesions in osteoneogenesis. Proc Inst Mech Eng $\mathrm{H}$ 2010;224:144I-53.

27. Oh S, Brammer KS, Li YS, Teng D, Engler AJ, Chien S, Jin S. Stem cell fate dictated solely by altered nanotube dimension. Proc Natl Acad Sci U S A 2009:106:2130-5.

28. Raimondo T, Puckett S, Webster TJ. Greater osteoblast and endothelial cell adhesion on nanostructured polyethylene and titanium. Int J Nanomedicine 2010;5:647-52.

29. Liu H,Webster TJ. Mechanical properties of dispersed ceramic nanoparticles in polymer composites for orthopedic applications. Int J Nanomedicine 20I0;5:299-3।3.

30. Poinern GJ, Brundavanam R, Le XT, Djordjevic S, Prokic M, Fawcett D. Thermal and ultrasonic influence in the formation of nanometer scale hydroxyapatite bio-ceramic. Int J Nanomedicine 201 I;6:2083-95.

31. Abd El-Fattah H, Helmy Y, El-Kholy B, Marie M. In vivo animal histomorphometric study for evaluating biocompatibility and osteointegration of nano-hydroxyapatite as biomaterials in tissue engineering.J Egypt Natl Canc Inst 2010;22:24I-50.

32. Polini A, Pisignano D, Parodi M, Quarto R, Scaglione S. Osteoinduction of human mesenchymal stem cells by bioactive composite scaffolds without supplemental osteogenic growth factors. PLoS One 201 I;6:e262II.

33. Bhardwaj A, Bhardwaj A, Misuriya A, Maroli S, Manjula S, Singh AK. Nanotechnology in dentistry: present and future. J Int Oral Health 2014;6:121-6.

34. Uskokovic V, Desai TA. Simultaneous bactericidal and osteogenic effect of nanoparticulate calcium phosphate powders loaded with clindamycin on osteoblasts infected with Staphylococcus aureus. Mater Sci Eng C Mater Biol Appl 2014;37:210-22.

35. Zheng Z, Yin W, Zara JN, Li W, Kwak J, Mamidi R, Lee M, Siu RK, Ngo R, Wang J, Carpenter D, Zhang X, Wu B, Ting K, Soo C. The use of BMP-2 coupled-Nanosilver-PLGA composite grafts to induce bone repair in grossly infected segmental defects. Biomaterials 2010;31:9293-300. 
36. Kose N, Otuzbir A, Peksen C, Kiremitci A, Dogan A. A silver ion-doped calcium phosphate-based ceramic nanopowder-coated prosthesis increased infection resistance. Clin Orthop Relat Res 2013;471:2532-9.

37. Leong PL, Morgan EF. Measurement of fracture callus material properties via nanoindentation. Acta Biomater 2008;4:I569-75.

38. Singhal S, Nie S, Wang MD. Nanotechnology applications in surgical oncology. Annu Rev Med 2010;61:359-73.
How to cite this article: Petersen DK, Naylor TM, Ver Halen JP. Current and future applications of nanotechnology in plastic and reconstructive surgery. Plast Aesthet Res 2014;1:43-50.

Source of Support: Nil, Conflict of Interest: None declared.

Received: 25-05-2014; Accepted: 20-07-2014 